Article

\title{
Synthesis of Some New Pyridazine Derivatives for Anti-HAV Evaluation
}

\author{
Eman M. Flefel ${ }^{1,2, *}$, Waled A. Tantawy ${ }^{2}$, Walaa I. El-Sofany ${ }^{2}$, Mahmoud El-Shahat ${ }^{2}$, \\ Ahmed A. El-Sayed ${ }^{2}$ and Dina N. Abd-Elshafy ${ }^{3}$ \\ 1 Department of Chemistry, College of Science, Taibah University, Al-Madinah Al-Monawarah 1343, \\ Saudi Arabia \\ 2 Department of Photochemistry, Chemical Industries Research Division, National Research Centre, \\ 33 EL-Bohouth St., Dokki 12622, Giza, Egypt; walednrc@gmail.com (W.A.T.); \\ walaa.elsofany@gmail.com (W.I.E.-S.); mahmoudelshahat@gmail.com (M.E.-S.); \\ ahmedcheme4@yahoo.com (A.A.E.-S.) \\ 3 Department of Water Pollution, Environmental Research Division, National Research Centre, \\ 33 EL-Bohouth St., Dokki 12622, Giza, Egypt; dnanadeem@yahoo.com \\ * Correspondence: emanmflefel@yahoo.com; Tel.: +966-593115502
}

Academic Editor: Derek J. McPhee

Received: 9 December 2016; Accepted: 10 January 2017; Published: 17 January 2017

Abstract: 4-(2-(4-Halophenyl)hydrazinyl)-6-phenylpyridazin-3(2H)-ones $\mathbf{1 a}, \mathbf{b}$ were prepared and treated with phosphorus oxychloride, phosphorus pentasulphide and ethyl chloroformate to give the corresponding chloropyridazine, pyridazinethione, oxazolopyridazine derivatives $\mathbf{2 - 4}$, respectively. Compound 2 reacted with hydrazine hydrate to afford hydrazinylpyridazine 7 . The reaction of 4-(2-(4-chlorophenyl)hydrazinyl)-3-hydrazinyl-6-phenylpyridazine (7) with acetic anhydride, $p$-chlorobenzaldehyde and carbon disulphide gave the corresponding pyridazinotriazine derivatives 8-10. On the other hand, 5-(4-chlorophenylamino)-7-(3,5-dimethoxybenzylidene)-3-phenyl-5Hpyridazino[3,4-b][1,4]thiazin-6(7H)-one (11) was prepared directly from the reaction of compound 3 with chloroacetic acid in presence of $p$-chlorobenzaldehyde. Compound $\mathbf{1 1}$ reacted with nitrogen nucleophiles (hydroxylamine hydrochloride, hydrazine hydrate) and active methylene group-containing reagents (malononitrile, ethyl cyanoacetate) to afford the corresponding fused compounds 12-15, respectively. Pharmacological screening for antiviral activity against hepatitis A virus (HAV) was performed for the new compounds. 4-(4-Chlorophenylamino)-6-phenyl-1,2dihydropyridazino[4,3-e][1,2,4]triazine-3(4H)-thione (10) showed the highest effect against HAV.

Keywords: pyridazine; fused pyridazine derivatives; hepatitis A virus (HAV)

\section{Introduction}

Heterocyclic compounds based on the pyridazine backbone have been cited as significant biologically active pharmacophores in the field of medicinal chemistry, providing a wide range of safe and effective drugs [1-6]. The pyridazine ring is thus a part of the structures of some therapeutic agents available on the market like cadralazine [7,8], minaprine [9-11], hydralazine [12,13], pipofezine [14], etc. (Figure 1).
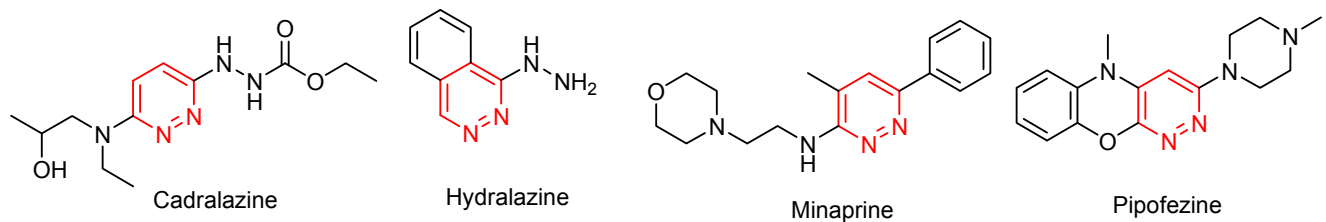

Figure 1. Some example of common drugs based on pyridazine rings. 
Pyridazine-based frameworks are widely distributed in biologically active products with anti-viral [15-20], anti-inflammatory [21-25], anti-microbial [26-28], anti-cancer [29-36], anti-convulsant [37-40], anti-analgesic [41,42], anti-tubercular [43-45], anti-hypertensive [3,46], anti-diabetic [47], anti-depressant [48,49], anti-Alzheimer's [50,51], phosphodiesterase [52,53], platelet aggregation [54-57], and cholesterol acyl transferase inhibitor properties [58]. Peptide nucleic acids (PNAs) with new pyridazine-type nucleobases were reported as replacements for the DNA duplex bases instead of thymine, adenine, guanine and cytosine to form novel DNA or RNA duplexes [59]. Hepatitis A is a highly contagious liver infection caused by the hepatitis A virus (HAV); it is usually transmitted by the fecal-oral route, either through person-to-person contact or consumption of contaminated food or water [60]. Hepatitis A is a self-limited disease that does not result in chronic infection. Tens of millions of infections are reported each year, with a higher incidence in developing countries. HAV infection causes fever, malaise, weakness, anorexia, nausea, vomiting, arthralgias and myalgias [61,62]. Although there are no commercial antiviral drugs specifically licensed for treating HAV infections, ribavirin, amentadine and 2-deoxy-D-glucose are among several antiviral substances known to interfere with HAV replication [63]. Many heterocyclic compounds were reported as anti HAV agents [64-67]. In view of these observations much attention has been devoted to develop novel pyridazines-based drug candidates. We report herein the synthesis of some new heterocyclic compounds containing pyridazine moieties and the study of their anti-viral activities compared to amentadine as positive control.

\section{Results and Discussion}

\subsection{Chemistry}

The 4-(2-(4-halophenyl)hydrazinyl)-6-phenylpyridazin-3(2H)-one compounds $\mathbf{1 a}, \mathbf{b}$ were prepared by refluxing 3-[2-(4-halophenyl)hydrazono]-5-phenylfuran-2(3H)-ones with hydrazine hydrate in absolute ethanol [68]. Compound 1a was reacted with phosphorus oxychloride to afford the 3-chloropyridazine derivative 2. The IR spectrum of compound 2 revealed the absence of a $\mathrm{C}=\mathrm{O}$ signal. The reaction of compound 1a with phosphorus pentasulphide afforded pyridazinethione derivative 3 . The same pyridazinethione 3 was also obtained when the 3-chloropyridazine derivative 2 was reacted with thiourea via the reaction of an unisolated thiouronium salt. The IR spectrum of pyridazinethione 3 showed the absence of a $\mathrm{C}=\mathrm{O}$ group and the presence of a characteristic $\mathrm{C}=\mathrm{S}$ group band at $1228 \mathrm{~cm}^{-1}$. On the other hand, when compound $\mathbf{1} \mathbf{b}$ was treated with ethyl chloroformate in the presence of anhydrous potassium carbonate it afforded the oxazolopyridazine 4 . This was treated with ammonium acetate in the presence of $\mathrm{ZnCl}_{2}$ to give imidazopyridazinone 5 . Heating a mixture of imidazopyridazinone 5 with ethyl bromoacetate in the presence of anhydrous potassium carbonate in acetone produced the pyridazinoimidazo oxadiazinone 6 (Scheme 1). The ${ }^{1} \mathrm{H}-\mathrm{NMR}$ spectrum of compound 6 showed signals at $4.09\left(\mathrm{~d}, J=11.63 \mathrm{~Hz}, 1 \mathrm{H}, \mathrm{CH}_{2}\right), 4.19\left(\mathrm{~d}, J=11.71 \mathrm{~Hz}, 1 \mathrm{H}, \mathrm{CH}_{2}\right)$ and the mass spectrum showed the expected molecular ion peak at $m / z(\%) 421$ (11).

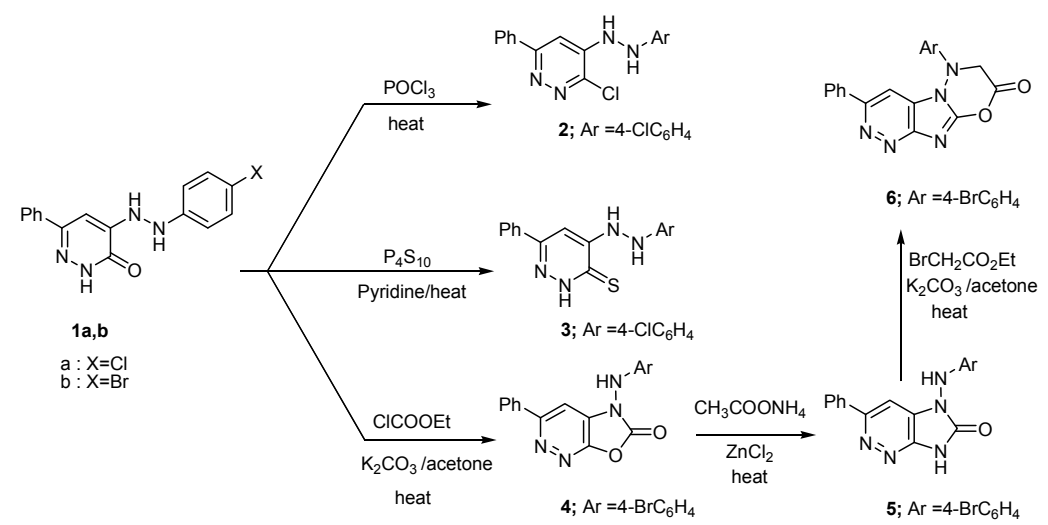

Scheme 1. General methods for preparation of compounds 2-6. 
When 3-chloropyridazine derivative 2 was refluxed with hydrazine hydrate it afforded the hydrazinopyridazine derivative 7 . The IR and ${ }^{1} \mathrm{H}-\mathrm{NMR}$ spectra of the latter compound revealed the presence of an $\mathrm{NH}_{2}$ group. The potential importance of compound 7 as an interesting intermediate induced us to explore its utility in the synthesis of new fused heterocyclic compounds.

Thus, its reactions with acetic anhydride, $p$-chlorobenzaldehyde and carbon disulphide afforded the corresponding pyridazinotriazine derivatives 8-10, respectively (Scheme 2). The spectra of compounds 8-10 revealed the absence of the corresponding $\mathrm{NH}_{2}$ group bands present in the parent hydrazinopyridazine derivative 7 .

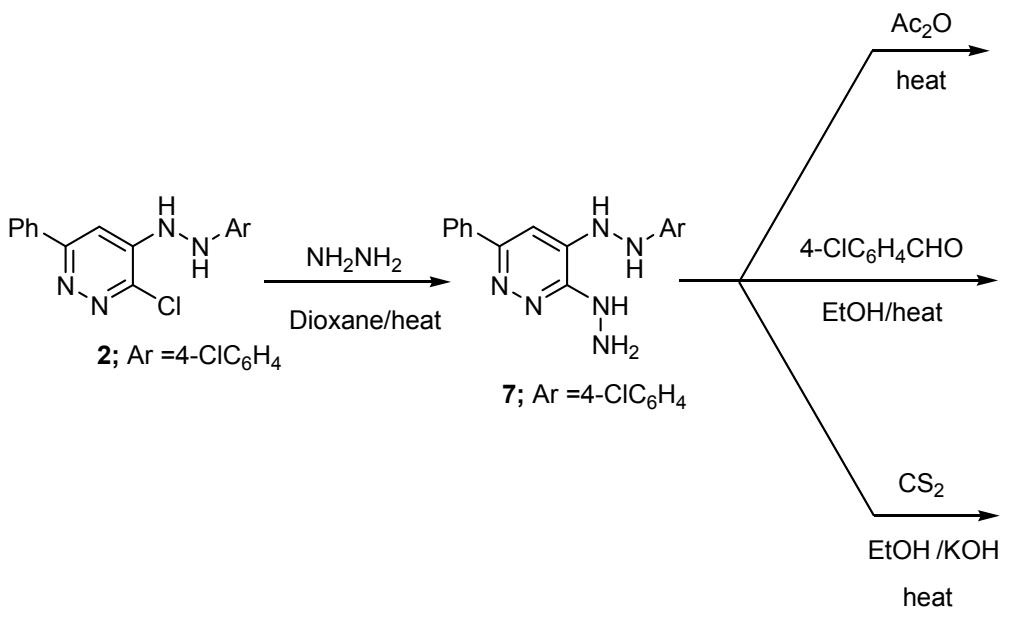

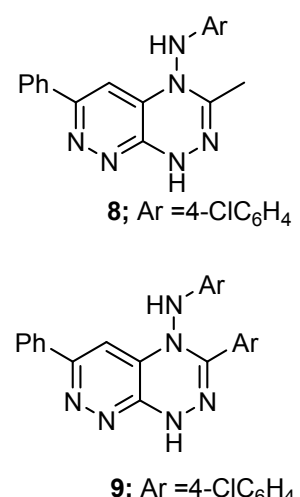<smiles>O=C(NN1C(=S)NNc2nnc(-c3ccccc3)cc21)c1ccccc1</smiles>

Scheme 2. General methods for preparation of compounds 7-10.

Moreover, 5-(4-chlorophenylamino)-7-(3,5-dimethoxybenzylidene)-3-phenyl-5H-pyridazino[3,4- $b$ ] $[1,4]$ thiazin-6(7H)-one (11) was prepared directly from pyridazinethione derivative 3 in a one-pot reaction by reaction with chloroacetic acid, $p$-chlorobenzaldehyde and anhydrous sodium acetate in a mixture of acetic acid/acetic anhydride. The IR spectrum of compound $\mathbf{1 1}$ showed the absence of a $C=S$ band and presence of a characteristic $C=O$ group band at $1697 \mathrm{~cm}^{-1}$, while the ${ }^{1} \mathrm{H}-\mathrm{NMR}$ spectrum showed a signal at $\delta 8.33(\mathrm{~s}, 1 \mathrm{H}, \mathrm{CH}$, exocyclic-H) (cf. Materials and Methods Section). Finally, compound $\mathbf{1 1}$ was used as a key starting material to synthesize a variety of fused heterocyclic compounds. The reaction of compound $\mathbf{1 1}$ with nitrogen nucleophiles, namely hydroxylamine hydrochloride and hydrazine hydrate and active methylene group reagents, namely malononitrile, and ethyl cyanoacetate, afforded the corresponding fused compounds 12-15, respectively (Scheme 3). The structure of these compounds was determined on the basis of elemental analysis and spectral data. The IR spectra of compounds 12 and 13 showed the absence of $\mathrm{C}=\mathrm{O}$ bands and the ${ }^{1} \mathrm{H}-\mathrm{NMR}$ of compound 14 revealed signals for two $\mathrm{OCH}_{3}$ groups at $\delta 3.80$ and 3.81 and an $\mathrm{NH}_{2}$ group at 5.3 (s, $2 \mathrm{H}, \mathrm{NH}_{2}, \mathrm{D}_{2} \mathrm{O}$ exchangeable). The IR spectrum showed absorption bands for $\mathrm{NH}_{2}\left(3355 \mathrm{~cm}^{-1}\right)$, and $\mathrm{CN}\left(2222 \mathrm{~cm}^{-1}\right)$ groups. On the other hand, The IR spectrum of compound 15 showed absorption bands for $\mathrm{C}=\mathrm{O}\left(1680 \mathrm{~cm}^{-1}\right), \mathrm{CN}\left(2221 \mathrm{~cm}^{-1}\right)$ and $2 \mathrm{NH}(3130$ and 3166$)$ groups (cf. the Materials and Methods Section). 


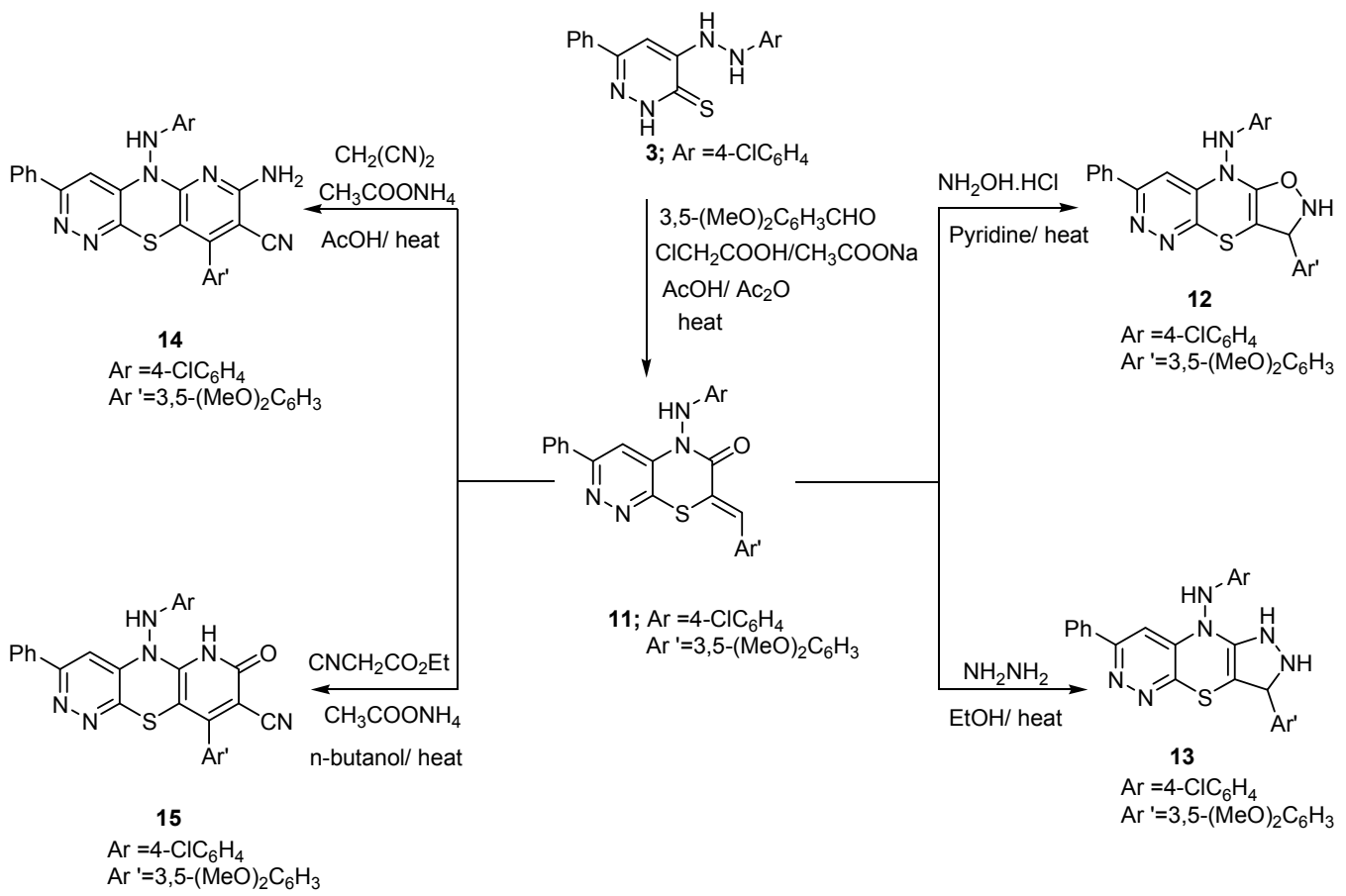

Scheme 3. General methods for preparation of compounds 11-15.

\subsection{Antiviral Screening}

In the present work we also report the anti-HAV activity results of the novel synthesized compounds. First, a cytotoxicity test was performed to determine safe doses that could be used in the antiviral assays without harming the HEPG2 cells (Table 1).

Table 1. Safe doses of each compound.

\begin{tabular}{ccccccc}
\hline \multirow{2}{*}{ Compounds } & \multicolumn{6}{c}{ Concentrations $(\mu \mathrm{g} / \mathrm{mL}) *$} \\
\cline { 2 - 7 } & $\mathbf{5}$ & $\mathbf{1 0}$ & $\mathbf{1 5}$ & $\mathbf{2 0}$ & $\mathbf{2 5}$ & $\mathbf{3 0}$ \\
\hline $\mathbf{2}$ & - & - & - & +2 & +3 & +3 \\
$\mathbf{3}$ & - & - & - & - & - & - \\
$\mathbf{4}$ & - & - & - & - & - & - \\
$\mathbf{5}$ & - & - & - & - & - & - \\
$\mathbf{6}$ & - & - & - & - & - & - \\
$\mathbf{8}$ & - & - & - & +1 & +2 & +4 \\
$\mathbf{9}$ & - & - & - & +1 & +2 & +4 \\
$\mathbf{1 0}$ & - & - & - & +2 & +3 & +4 \\
$\mathbf{1 1}$ & - & - & - & - & - & +1 \\
$\mathbf{1 2}$ & - & - & - & - & - & - \\
$\mathbf{1 3}$ & - & - & - & +1 & +2 & +3 \\
$\mathbf{1 4}$ & - & - & - & - & - & - \\
$\mathbf{1 5}$ & - & - & +1 & +3 & +4 & +4 \\
\hline
\end{tabular}

* Safe doses, $+1: 25 \%$ of cell sheet was affected, $+2: 50 \%$ of cell sheet was affected, $+3: 75 \%$ of cell sheet was affected, $+4: 100 \%$ of cell sheet was affected.

Safe concentrations were used in a plaque reduction assay which was made to detect any changes in viral count as a result of being treated with the compounds with respect to untreated control. Results (Table 2) showed that compound $\mathbf{1 0}$ has high antiviral activity against HAV on comparing the effect of different concentrations of compound $\mathbf{1 0}$ with the same concentrations of amentadine (positive control). The results (Figure 2) showed that compound $\mathbf{1 0}$ has higher inhibitory effect than amentadine at the five concentrations used. 
Table 2. The antiviral activity of the synthesized compounds against HAV.

\begin{tabular}{|c|c|c|}
\hline Compound & Concentration $(\mu \mathrm{g} / \mathrm{mL})$ & $\%$ Inhibition \\
\hline \multirow[b]{2}{*}{2} & 10 & 13 \\
\hline & 15 & 29 \\
\hline \multirow[b]{2}{*}{3} & 20 & 19 \\
\hline & 25 & 66 \\
\hline \multirow{2}{*}{4} & 20 & 56 \\
\hline & 25 & 73 \\
\hline \multirow{2}{*}{5} & 20 & 30 \\
\hline & 25 & 62 \\
\hline \multirow{2}{*}{6} & 20 & 0 \\
\hline & 25 & 0 \\
\hline \multirow{2}{*}{8} & 10 & 26 \\
\hline & 15 & 65 \\
\hline \multirow{2}{*}{9} & 10 & 37 \\
\hline & 15 & 50 \\
\hline \multirow{2}{*}{10} & 10 & 100 \\
\hline & 15 & 100 \\
\hline \multirow{2}{*}{11} & 20 & 50 \\
\hline & 25 & 75 \\
\hline \multirow{2}{*}{12} & 20 & 42 \\
\hline & 25 & 37 \\
\hline \multirow{2}{*}{13} & 10 & 33 \\
\hline & 15 & 4 \\
\hline \multirow{2}{*}{14} & 20 & 46 \\
\hline & 25 & 76 \\
\hline \multirow{2}{*}{15} & 10 & 0 \\
\hline & 15 & 38 \\
\hline
\end{tabular}

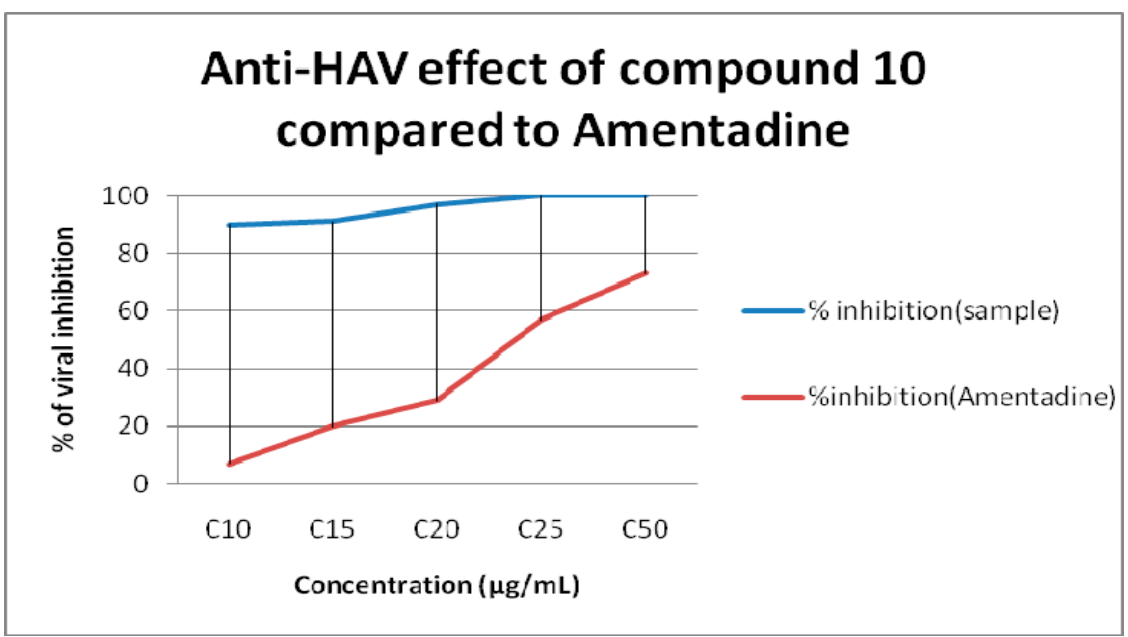

Figure 2. Anti HAV activity of compound 10 compared to amentadine as positive control, C: concentration.

The possible mechanism of action of compound $\mathbf{1 0}$ was also studied and the results (Figure 3) showed that it has a high virucidal effect and it also shows a mild effect on viral replication. This can be explained by the notion that compound $\mathbf{1 0}$ was able to bind to the HAV capsid and thus change its configuration, causing an inability of the virus to bind to its cell receptor, or the compound might also 
react with the proteins of the capsid also resulting in its inactivation. For its mild effect on replication, this might be due to a mild inhibitory effect of the compound on one or more enzymes needed by the virus to complete its replication cycle, and as a result, showing the observed decrease in viral count. On the other hand the compound has no effect on viral adsorption.

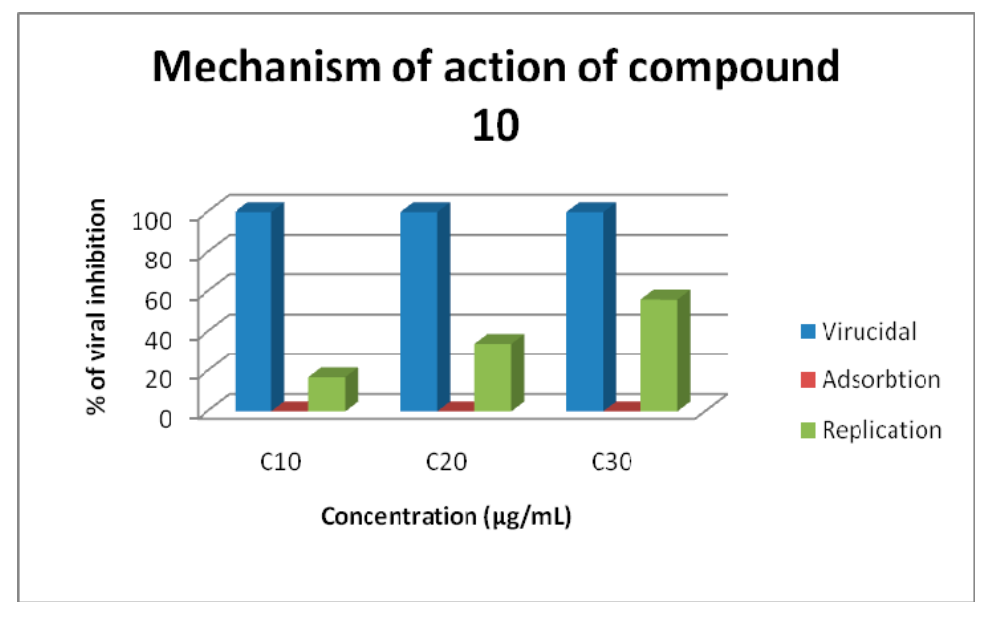

Figure 3. Virucidal effect on viral replication.

\section{Materials and Methods}

\subsection{General Inforation}

Melting points were measured using an Electrothermal 9100 digital melting point apparatus (Büchi, Flawil, Switzerland) and are uncorrected. IR spectra were recorded on a Perkin-Elmer 1600 FTIR (Perkin-Elmer, Waltham, MA, USA) in KBr discs. ${ }^{1} \mathrm{H}-\mathrm{NMR}$ spectra (300 MHz) were measured on a Jeol $270 \mathrm{MHz}$ spectrometer (Jeol, Tokyo, Japan) or an Avance spectrometer (Bruker, Karlsruhe, Germany) in DMSO- $d_{6}$, and chemical shifts were recorded in $\delta$ ppm relative to the internal standard TMS. The mass spectra were run at $70 \mathrm{eV}$ with a Finnigan SSQ 7000 spectrometer (Thermo Electron Corporation, Madison, WI, USA) using EI and the values of $m / z$ are indicated in Dalton. Elemental analyses were performed on a Perkin-Elmer 2400 analyzer (Perkin-Elmer) and were found within $\pm 0.4 \%$ of the theoretical values. Reaction monitoring and verification of the purity of the compounds was done by TLC on silica gel-precoated aluminum sheets (type 60 F254, Merck, Darmstadt, Germany). All solvents and chemical reagents were purchased from Aldrich (Munich, Germany).

\subsection{Chemistry}

\subsubsection{3-Chloro-4-(2-(4-chlorophenyl)hydrazinyl)-6-phenylpyridazine (2)}

A mixture of $\mathbf{1 a}(0.01 \mathrm{~mol})$ and phosphorus oxychloride $(10 \mathrm{~mL})$ was refluxed for $4 \mathrm{~h}$. The mixture was cooled, poured onto crushed ice and then neutralized with $4 \% \mathrm{NaOH}$. The precipitate was collected by filtration, washed with water and recrystallized from benzene to give compound 2. Yield 86\%, m.p. 179-181 ${ }^{\circ} \mathrm{C}$; IR $\left(v, \mathrm{~cm}^{-1}\right): 3140,3153(2 \mathrm{NH}) ;{ }^{1} \mathrm{H}-\mathrm{NMR}(\delta \mathrm{ppm}): 4.35$ (s, 1H, NH; $\mathrm{D}_{2} \mathrm{O}$ exchangeable), 4.40 (s, 1H, NH; $\mathrm{D}_{2} \mathrm{O}$ exchangeable), 6.64 (s, 1H, pyridazine-H), 6.71-7.97 (m, 9H, Ar-H); MS, m/z (\%): $330\left(\mathrm{M}^{+}, 68\right), 332\left(\mathrm{M}^{+}+2,41\right), 334\left(\mathrm{M}^{+}+4,7\right)$. Analysis for $\mathrm{C}_{16} \mathrm{H}_{12} \mathrm{Cl}_{2} \mathrm{~N}_{4}$ (331.21): calcd. C, 58.02; $\mathrm{H}, 3.65 ; \mathrm{Cl}, 21.41 ; \mathrm{N}, 16.92$. Found: $\mathrm{C}, 57.83 ; \mathrm{H}, 3.39 ; \mathrm{Cl}, 21.08 ; \mathrm{N}, 16.59$.

\subsubsection{4-(2-(4-Chlorophenyl)hydrazinyl)-6-phenylpyridazine-3(2H)-thione (3)}

Method A. A mixture of 1a $(0.01 \mathrm{~mol})$ and phosphorus pentasulphide $(0.01 \mathrm{~mol})$ in dry pyridine $(20 \mathrm{~mL})$ was refluxed for $5 \mathrm{~h}$. After cooling, the reaction mixture was poured onto ice and neutralized with 
ammonia solution $30 \%$. The separated solid was filtered off, dried and recrystallized from methanol to give compound 3 with yield $50 \%$.

Method B. A mixture of $2(0.01 \mathrm{~mol})$ and thiourea $(0.01 \mathrm{~mol})$ in $n$-propanol $(40 \mathrm{~mL})$ was refluxed for $4 \mathrm{~h}$. The formed precipitate was collected and dissolved in $10 \% \mathrm{NaOH}(20 \mathrm{~mL})$. The mixture was filtered off and the filtrate was precipitated with $\mathrm{HCl}(0.1 \mathrm{~N})$. The solid produced was collected and recrystallized from methanol to give compound identical in all aspects with compound $\mathbf{3}$ (m.p., mixed m.p., TLC). Yield 30\%, m.p. $210-212^{\circ} \mathrm{C}$; IR $\left(v, \mathrm{~cm}^{-1}\right)$ : 3190-3140 (3NH), $1228(\mathrm{C}=\mathrm{S}) ;{ }^{1} \mathrm{H}-\mathrm{NMR}(\delta \mathrm{ppm})$ : $3.89\left(\mathrm{~s}, 1 \mathrm{H}, \mathrm{NH} ; \mathrm{D}_{2} \mathrm{O}\right.$ exchangeable), $4.4\left(\mathrm{~s}, 1 \mathrm{H}, \mathrm{NH} ; \mathrm{D}_{2} \mathrm{O}\right.$ exchangeable), $6.62(\mathrm{~s}, 1 \mathrm{H}$, pyridazine- $\mathrm{H})$, 6.7-7.98 (m, 9H, Ar-H), 8.71(s, 1H, NH; $\mathrm{D}_{2} \mathrm{O}$ exchangeable); $\mathrm{MS}, \mathrm{m} / \mathrm{z}(\%): 328\left(\mathrm{M}^{+}, 62\right), 330\left(\mathrm{M}^{+}+2,20\right)$. Analysis for $\mathrm{C}_{16} \mathrm{H}_{13} \mathrm{ClN}_{4} \mathrm{~S}$ (328.83): calcd. C, 58.44; $\mathrm{H}, 3.98 ; \mathrm{Cl}, 10.78 ; \mathrm{N}, 17.04 ; \mathrm{S}, 9.75$. Found C, 58.17; $\mathrm{H}, 3.42 ; \mathrm{Cl}, 10.47 ; \mathrm{N}, 16.79 ; \mathrm{S}, 9.51$.

\subsubsection{5-(4-Bromophenylamino)-3-phenyloxazolo[5,4-c]pyridazin-6(5H)-one (4)}

A mixture of compound $\mathbf{1 b}(0.01 \mathrm{~mol})$, ethyl chloroformate $(0.01 \mathrm{~mol})$ and anhydrous potassium carbonate $(0.04 \mathrm{~mol})$ in dry acetone $(30 \mathrm{~mL})$ was refluxed for $20 \mathrm{~h}$. The excess of solvent was evaporated then poured onto water. The solid obtained was filtered off and crystallized from ethanol to give compound 4. Yield $61 \%$, m.p. $173-175^{\circ} \mathrm{C}$. IR spectrum $\left(v, \mathrm{~cm}^{-1}\right): 3228(\mathrm{NH}), 1715(\mathrm{C}=\mathrm{O}) .{ }^{1} \mathrm{H}-\mathrm{NMR}$ ( $\delta \mathrm{ppm}): 4.41\left(\mathrm{~s}, 1 \mathrm{H}, \mathrm{NH} ; \mathrm{D}_{2} \mathrm{O}\right.$ exchangeable), 6.67(s, $1 \mathrm{H}$, pyridazine- $\left.\mathrm{H}\right), 7.26-8.26(\mathrm{~m}, 9 \mathrm{H}, \mathrm{Ar}-\mathrm{H})$; MS, $m / z(\%): 382\left(\mathrm{M}^{+}, 67\right), 384\left(\mathrm{M}^{+}+2\right.$, 63). Analysis for $\mathrm{C}_{17} \mathrm{H}_{11} \mathrm{BrN}_{4} \mathrm{O}_{2}$ (383.21): calcd. C, 53.28; $\mathrm{H}, 2.89 ; \mathrm{Br}, 20.85 ; \mathrm{N}, 14.62$. Found C, 55.97; H, 2.61; Br, 20.37; N, 14.35 .

\subsubsection{5-(4-Bromophenylamino)-3-phenyl-5H-imidazo[4,5-c]pyridazin-6(7H)-one (5)}

A mixture of compound $4(0.01 \mathrm{~mol})$, ammonium acetate $(0.03 \mathrm{~mol})$ and a catalytic amount of $\mathrm{ZnCl}_{2}$ was fused in an oil-bath for $3 \mathrm{~h}$. Then the mixture was poured onto water, and the resultant solid was filtered and recrystallized from dioxane to give 5. Yield $51 \%$, m.p. $180-182^{\circ} \mathrm{C}$. IR spectrum $\left(v, \mathrm{~cm}^{-1}\right): 3220-3142(2 \mathrm{NH}), 1688(\mathrm{C}=\mathrm{O}) .{ }^{1} \mathrm{H}-\mathrm{NMR}(\delta \mathrm{ppm}): 4.32\left(\mathrm{~s}, 1 \mathrm{H}, \mathrm{NH} ; \mathrm{D}_{2} \mathrm{O}\right.$ exchangeable), 6.40 (s, $1 \mathrm{H}, \mathrm{NH} ; \mathrm{D}_{2} \mathrm{O}$ exchangeable), $6.82(\mathrm{~s}, 1 \mathrm{H}$, pyridazine-H), 7.66-8.35 (m, $9 \mathrm{H}, \mathrm{Ar}-\mathrm{H}) ; \mathrm{MS}, \mathrm{m} / z(\%)$ : $381\left(\mathrm{M}^{+}\right.$, 24), $383\left(\mathrm{M}^{+}+2\right.$, 22). Analysis for $\mathrm{C}_{17} \mathrm{H}_{12} \mathrm{BrN}_{5} \mathrm{O}$ (382.22): calcd. C, 53.42; $\mathrm{H}, 3.16 ; \mathrm{Br}, 20.91$; $\mathrm{N}, 18.32$. Found C, 53.15; H, 2.87; Br, 20.65; N, 18.01 .

3.2.5. 6-(4-Bromophenyl)-3-phenyl-6,7-dihydro-8H-pyridazino[ $\left[3^{\prime}, 4^{\prime}: 4,5\right]$ imidazo[2,1-b][1,3,4]oxadiazin8-one (6)

A mixture of compound $5(0.01 \mathrm{~mol})$, ethyl bromoacetate $(0.01 \mathrm{~mol})$ and anhydrous potassium carbonate $(0.04 \mathrm{~mol})$ in dry acetone $(30 \mathrm{~mL})$ was refluxed for $12 \mathrm{~h}$; the excess of solvent was evaporated and the reaction mixture then poured onto water. The solid obtained was filtered off and crystallized from methanol to give 6. Yield 44\%, m.p. $199-201{ }^{\circ} \mathrm{C}$. IR spectrum $\left(v, \mathrm{~cm}^{-1}\right): 1703(\mathrm{C}=\mathrm{O}) .{ }^{1} \mathrm{H}-\mathrm{NMR}$

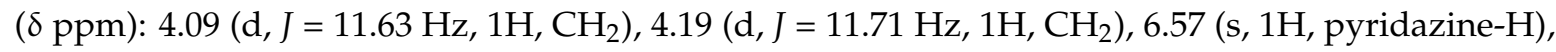
7.33-8.42 (m, $9 \mathrm{H}, \mathrm{Ar}-\mathrm{H})$; MS, $m / z(\%)$ : $421\left(\mathrm{M}^{+}, 11\right), 423\left(\mathrm{M}^{+}+2,9\right)$. Analysis for $\mathrm{C}_{19} \mathrm{H}_{12} \mathrm{BrN}_{5} \mathrm{O}_{2}$ (422.24): calcd. C, 54.05; H, 2.86; Br, 18.92; N, 16.59. Found C, 53.76; H, 2.55; Br, 18.60; N, 16.29.

\subsubsection{4-(2-(4-Chlorophenyl)hydrazinyl)-3-hydrazinyl-6-phenylpyridazine (7)}

A mixture of $2(0.01 \mathrm{~mol})$ and hydrazine hydrate $(99 \%, 0.01 \mathrm{~mol})$ in dioxane $(20 \mathrm{~mL})$ was heated under reflux for $6 \mathrm{~h}$, the formed solid was filtered off and crystallized from ethanol to give 7. Yield $55 \%$; m.p. $102-104{ }^{\circ} \mathrm{C}$; IR $\left(v, \mathrm{~cm}^{-1}\right): 3350\left(\mathrm{NH}_{2}\right), 3192-3135$ (3NH); ${ }^{1} \mathrm{H}-\mathrm{NMR}(\delta \mathrm{ppm}): 4.38(\mathrm{~s}, 1 \mathrm{H}, \mathrm{NH}$; $\mathrm{D}_{2} \mathrm{O}$ exchangeable), 4.45 (s, $1 \mathrm{H}, \mathrm{NH} ; \mathrm{D}_{2} \mathrm{O}$ exchangeable), $5.14\left(\mathrm{~s}, 2 \mathrm{H}, \mathrm{NH}_{2} ; \mathrm{D}_{2} \mathrm{O}\right.$ exchangeable), 6.64 (s, 1H, pyridazine-H), 7.17-8.31 (m, 9 H, Ar-H), 8.89 (s, 1H, NH; $\mathrm{D}_{2} \mathrm{O}$ exchangeable); $\mathrm{MS}, \mathrm{m} / z$ (\%): 326 $\left(\mathrm{M}^{+}, 70\right), 328\left(\mathrm{M}^{+}+2,24\right)$. Analysis for $\mathrm{C}_{16} \mathrm{H}_{15} \mathrm{ClN}_{6}$ (326.79): calcd. $\mathrm{C}, 58.81 ; \mathrm{H}, 4.63 ; \mathrm{Cl}, 10.85 ; \mathrm{N}, 25.72$. Found C, 58.56; H, 4.31; Cl, 10.57; N, 25.44. 
3.2.7. $\mathrm{N}$-(4-Chlorophenyl)-3-methyl-6-phenylpyridazino[4,3-e][1,2,4]triazin-4(1H)-amine (8)

A solution of $7(0.01 \mathrm{~mol})$ and acetic anhydride $(20 \mathrm{~mL})$ was heated under reflux for $2 \mathrm{~h}$. The solid obtained after cooling was crystallized from acetic acid to give 8. Yield $46 \%$; m.p. $125-127^{\circ} \mathrm{C} ; \mathrm{IR}\left(\mathrm{v}, \mathrm{cm}^{-1}\right)$ : 3180, $3132(2 \mathrm{NH}) ;{ }^{1} \mathrm{H}-\mathrm{NMR}(\delta \mathrm{ppm}): 2.38$ (s, 3H, $\left.\mathrm{CH}_{3}\right), 4.35$ (s, $1 \mathrm{H}, \mathrm{NH} ; \mathrm{D}_{2} \mathrm{O}$ exchangeable), $6.7(\mathrm{~s}, 1 \mathrm{H}$, pyridazine-H), 7.27-8.35 (m, 9H, Ar-H), $8.96\left(\mathrm{~s}, 1 \mathrm{H}, \mathrm{NH}, \mathrm{D}_{2} \mathrm{O}\right.$ exchangeable); $\mathrm{MS}, m / z(\%): 350\left(\mathrm{M}^{+}, 14\right)$, $352\left(\mathrm{M}^{+}+2,4\right)$. Analysis for $\mathrm{C}_{18} \mathrm{H}_{15} \mathrm{ClN}_{6}$ (350.81): calcd. $\mathrm{C}, 61.63 ; \mathrm{H}, 4.31 ; \mathrm{Cl}, 10.11 ; \mathrm{N}, 23.96$. Found $\mathrm{C}$, $61.37 ; \mathrm{H}, 4.06 ; \mathrm{Cl}, 9.86 ; \mathrm{N}, 23.71$.

\subsubsection{N,3-Bis(4-chlorophenyl)-6-phenylpyridazino[4,3-e][1,2,4]triazin-4(1H)-amine (9)}

A mixture of $7(0.01 \mathrm{~mol})$ and $p$-chlorobenzaldehyde $(0.01 \mathrm{~mol})$ in ethanol $(20 \mathrm{~mL}) / \mathrm{HCl}(1 \mathrm{~mL})$ was heated under reflux for $2 \mathrm{~h}$, and then cooled. The separated solid was filtered, dried and crystallized from methanol to afford 9. Yield 50\%; m.p. $158-160{ }^{\circ} \mathrm{C}$; IR $\left(v, \mathrm{~cm}^{-1}\right): 3140 ; 3110(2 \mathrm{NH}) ;{ }^{1} \mathrm{H}-\mathrm{NMR}$ ( $\delta \mathrm{ppm}): 4.4\left(\mathrm{~s}, 1 \mathrm{H}, \mathrm{NH} ; \mathrm{D}_{2} \mathrm{O}\right.$ exchangeable), $6.66(\mathrm{~s}, 1 \mathrm{H}$, pyridazine- $\mathrm{H}), 7.10-8.81(\mathrm{~m}, 13 \mathrm{H}, \mathrm{Ar}-\mathrm{H})$, 8.91 (s, $1 \mathrm{H}, \mathrm{NH} ; \mathrm{D}_{2} \mathrm{O}$ exchangeable); $\mathrm{MS}, \mathrm{m} / \mathrm{z}(\%): 446\left(\mathrm{M}^{+}, 44\right), 448\left(\mathrm{M}^{+}+2,27\right), 450\left(\mathrm{M}^{+}+4,4\right)$. Analysis for $\mathrm{C}_{23} \mathrm{H}_{16} \mathrm{Cl}_{2} \mathrm{~N}_{6}$ (447.32): calcd. $\mathrm{C}, 61.76 ; \mathrm{H}, 3.61 ; \mathrm{Cl}, 15.85 ; \mathrm{N}, 18.79$. Found $\mathrm{C}, 61.51 ; \mathrm{H}, 3.35$; $\mathrm{Cl}, 15.60 ; \mathrm{N}, 18.63$.

\subsubsection{4-(4-Chlorophenylamino)-6-phenyl-1,2-dihydropyridazino[4,3-e][1,2,4]triazine-3(4H)-thione (10)}

A mixture of $7(0.01 \mathrm{~mol})$, carbon disulfide $(0.02 \mathrm{~mol})$ and $(0.01 \mathrm{~mol}) \mathrm{KOH}$ in ethanol $(50 \mathrm{~mL})$ was refluxed for $9 \mathrm{~h}$. The solvent was evaporated under vacuum, dissolved in hot water, and then the filtrate was neutralized with diluted hydrochloric acid. The precipitate was collected after washing with water several times. The product obtained was recrystallized from dioxane to give compound $\mathbf{1 0}$. Yield 43\%; m.p. $111-113{ }^{\circ} \mathrm{C}$; IR ( $\left.v, \mathrm{~cm}^{-1}\right)$ : 3144-3160 (3NH), $1230(\mathrm{C}=\mathrm{S}) ;{ }^{1} \mathrm{H}-\mathrm{NMR}(\delta \mathrm{ppm}): 4.44(\mathrm{~s}, 1 \mathrm{H}$, $\mathrm{NH} ; \mathrm{D}_{2} \mathrm{O}$ exchangeable), $5.04\left(\mathrm{~s}, 1 \mathrm{H}, \mathrm{NH} ; \mathrm{D}_{2} \mathrm{O}\right.$ exchangeable), $6.70(\mathrm{~s}, 1 \mathrm{H}$, pyridazine- $\mathrm{H}), 7.20-8.38$ (m, 9H, Ar-H), 8. 86 (s, $1 \mathrm{H}, \mathrm{NH} ; \mathrm{D}_{2} \mathrm{O}$ exchangeable); $\mathrm{MS}, \mathrm{m} / \mathrm{z}(\%): 368\left(\mathrm{M}^{+}, 56\right), 370\left(\mathrm{M}^{+}+2,20\right)$. Analysis for $\mathrm{C}_{17} \mathrm{H}_{13} \mathrm{ClN}_{6} \mathrm{~S}$ (368.85): calcd. $\mathrm{C}, 55.36 ; \mathrm{H}, 3.55 ; \mathrm{Cl}, 9.61 ; \mathrm{N}, 22.78 ; \mathrm{S}, 8.69$. Found C, 55.09; $\mathrm{H}, 3.39 ; \mathrm{Cl}, 9.37 ; \mathrm{N}, 22.51 ; \mathrm{S}, 8.44$.

3.2.10. 5-(4-Chlorophenylamino)-7-(3,5-dimethoxybenzylidene)-3-phenyl-5H-pyridazino[3,4-b][1,4] thiazin-6(7H)-one (11)

A mixture of $3(0.01 \mathrm{~mol})$, chloroacetic acid $(0.01 \mathrm{~mol})$, anhydrous sodium acetate $(0.01 \mathrm{~mol})$ in glacial acetic acid/acetic anhydride $(40 \mathrm{~mL}, 3: 1)$ and 3,4-dimethoxybenzaldehyde $(0.01 \mathrm{~mol})$ was added. The reaction mixture was heated under reflux for $3 \mathrm{~h}$, then cooled and poured onto water. The solid formed was collected by filtration and crystallized from dioxane to give compound 11. Yield $50 \%$; m.p. 106-108 ${ }^{\circ} \mathrm{C}$; IR $\left(v, \mathrm{~cm}^{-1}\right): 3150(\mathrm{NH}), 1697(\mathrm{C}=\mathrm{O}) ;{ }^{1} \mathrm{H}-\mathrm{NMR}(\delta \mathrm{ppm}): 3.85\left(\mathrm{~s}, 3 \mathrm{H}, \mathrm{OCH}_{3}\right), 3.86(\mathrm{~s}, 3 \mathrm{H}$, $\left.\mathrm{OCH}_{3}\right), 4.45\left(\mathrm{~s}, 1 \mathrm{H}, \mathrm{NH} ; \mathrm{D}_{2} \mathrm{O}\right.$ exchangeable), $6.82(\mathrm{~s}, 1 \mathrm{H}$, pyridazine- $\mathrm{H}), 7.38-7.90(\mathrm{~m}, 12 \mathrm{H}, \mathrm{Ar}-\mathrm{H}), 8.33$ (s, $1 \mathrm{H}$, exocyclic vinylic-H); MS, $m / z(\%): 516\left(\mathrm{M}^{+}, 47\right), 518\left(\mathrm{M}^{+}+2,16\right)$. Analysis for $\mathrm{C}_{27} \mathrm{H}_{21} \mathrm{ClN}_{4} \mathrm{O}_{3} \mathrm{~S}$ (517.01): calcd. C, 62.73; H, 4.09; Cl, 6.86; N, 10.84; S, 6.20. Found C, 62.45; H, 3.79; Cl, 6.57; N, 10.61; S, 5.88 .

3.2.11. N-(4-Chlorophenyl)-3-(3,5-dimethoxyphenyl)-7-phenyl-2,3-dihydro-9H-isoxazolo[4,5-b] pyridazino[4,3-e][1,4]thiazin-9-amine (12)

A mixture of $\mathbf{1 1}(0.01 \mathrm{~mol})$ and hydroxylamine hydrochloride $(0.01 \mathrm{~mol})$ was refluxed in pyridine $(5 \mathrm{~mL})$ for $10 \mathrm{~h}$. The reaction mixture was cooled, poured onto water $(100 \mathrm{~mL})$ and neutralized with dilute $\mathrm{HCl}$, the product was filtered, dried and crystallized from dioxane to give compound $\mathbf{1 2}$. Yield 58\%; m.p. $144-146{ }^{\circ} \mathrm{C}$; IR $\left(v, \mathrm{~cm}^{-1}\right)$ : 3150, $3110(2 \mathrm{NH}) ;{ }^{1} \mathrm{H}-\mathrm{NMR}(\delta \mathrm{ppm}): 3.84\left(\mathrm{~s}, 3 \mathrm{H}, \mathrm{OCH}_{3}\right), 3.85$ $\left(\mathrm{s}, 3 \mathrm{H}, \mathrm{OCH}_{3}\right), 4.46\left(\mathrm{~s}, 1 \mathrm{H}, \mathrm{NH} ; \mathrm{D}_{2} \mathrm{O}\right.$ exchangeable), $4.73(\mathrm{~s}, 1 \mathrm{H}$, isoxazole- $\mathrm{H}), 6.80(\mathrm{~s}, 1 \mathrm{H}$, pyridazine- $\mathrm{H})$, 7.11-7.92 (m, 12H, Ar-H), $8.92\left(\mathrm{~s}, 1 \mathrm{H}, \mathrm{NH} ; \mathrm{D}_{2} \mathrm{O}\right.$ exchangeable); MS, m/z (\%): $531\left(\mathrm{M}^{+}, 36\right), 533\left(\mathrm{M}^{+}\right.$ 
+2 , 13). Analysis for $\mathrm{C}_{27} \mathrm{H}_{22} \mathrm{ClN}_{5} \mathrm{O}_{3} \mathrm{~S}$ (532.03): calcd. C, 60.96; H, 4.17; $\mathrm{Cl}, 6.66 ; \mathrm{N}, 13.16 ; \mathrm{S}, 6.03$. Found $\mathrm{C}, 60.47 ; \mathrm{H}, 3.89 ; \mathrm{Cl}, 6.41 ; \mathrm{N}, 1.88 ; \mathrm{S}, 5.77$.

3.2.12. N-(4-Chlorophenyl)-3-(3,5-dimethoxyphenyl)-7-phenyl-2,3-dihydropyrazolo[4,3-b] pyridazino[4,3-e][1,4]thiazin-9(1H)-amine (13)

A mixture of compound $11(0.01 \mathrm{~mol})$ and hydrazine hydrate $(0.02 \mathrm{~mol})$ was refluxed in ethanol $(20 \mathrm{~mL})$ for $5 \mathrm{~h}$, then poured onto cold water. The solid substance was filtered off, dried and recrystallized from dioxane to give compound 13. Yield $62 \%$; m.p. $173-175^{\circ} \mathrm{C} ; \mathrm{IR}\left(\nu, \mathrm{cm}^{-1}\right): 3195-3111$ $(3 \mathrm{NH}) ;{ }^{1} \mathrm{H}-\mathrm{NMR}$ (DMSO- $\left.d_{6}, \delta \mathrm{ppm}\right): 3.80\left(\mathrm{~s}, 3 \mathrm{H}, \mathrm{OCH}_{3}\right), 3.82\left(\mathrm{~s}, 3 \mathrm{H}, \mathrm{OCH}_{3}\right), 4.43\left(\mathrm{~s}, 1 \mathrm{H}, \mathrm{NH}, \mathrm{D}_{2} \mathrm{O}\right.$ exchangeable), $4.83(\mathrm{~s}, 1 \mathrm{H}$, pyrazole- $\mathrm{H}), 6.69(\mathrm{~s}, 1 \mathrm{H}$, pyridazine- $\mathrm{H}), 7.11-7.90(\mathrm{~m}, 12 \mathrm{H}, \mathrm{Ar}-\mathrm{H}), 8.88$ (s, $1 \mathrm{H}, \mathrm{NH}, \mathrm{D}_{2} \mathrm{O}$ exchangeable) $9.08\left(\mathrm{~s}, 1 \mathrm{H}, \mathrm{NH}, \mathrm{D}_{2} \mathrm{O}\right.$ exchangeable); $\mathrm{MS}, \mathrm{m} / z(\%): 530\left(\mathrm{M}^{+}, 51\right), 532$ $\left(\mathrm{M}^{+}+2\right.$, 17). Analysis for $\mathrm{C}_{27} \mathrm{H}_{23} \mathrm{ClN}_{6} \mathrm{O}_{2} \mathrm{~S}$ (531.04): calcd. C, 61.07; $\mathrm{H}, 4.37 ; \mathrm{Cl}, 6.68 ; \mathrm{N}, 15.83 ; \mathrm{S}, 6.04$. Found $\mathrm{C}, 60.77 ; \mathrm{H}, 4.09 ; \mathrm{Cl}, 6.41 ; \mathrm{N}, 15.58 ; \mathrm{S}, 5.76$.

3.2.13. 7-Amino-5-((4-chlorophenyl)amino)-9-(3,5-dimethoxyphenyl)-3-phenyl-5H-pyridazino[3,4-b] pyrido[2,3-e][1,4]thiazine-8-carbonitrile (14)

A mixture of $11(0.01 \mathrm{~mol})$, malononitrile $(0.01 \mathrm{~mol})$, and anhydrous ammonium acetate $(0.02 \mathrm{~mol})$ was refluxed in glacial acetic acid $(40 \mathrm{~mL})$ for $24 \mathrm{~h}$. The reaction mixture was cooled and poured onto water. The formed solid was filtered off, dried and recrystallized from dioxane to give compound 14. Yield 60\%; m.p. 133-135 ${ }^{\circ} \mathrm{C}$; IR (KBr, v, cm ${ }^{-1}$ ): $3355(\mathrm{NH} 2), 3170(\mathrm{NH}), 2222(\mathrm{CN}) ;{ }^{1} \mathrm{H}-\mathrm{NMR}(\delta \mathrm{ppm})$ : $3.80\left(\mathrm{~s}, 3 \mathrm{H}, \mathrm{OCH}_{3}\right), 3.81\left(\mathrm{~s}, 3 \mathrm{H}, \mathrm{OCH}_{3}\right), 4.42\left(\mathrm{~s}, 1 \mathrm{H}, \mathrm{NH} ; \mathrm{D}_{2} \mathrm{O}\right.$ exchangeable), $5.3\left(\mathrm{~s}, 2 \mathrm{H}, \mathrm{NH}_{2}\right.$; $\mathrm{D}_{2} \mathrm{O}$ exchangeable), $6.79\left(\mathrm{~s}, 1 \mathrm{H}\right.$, pyridazine-H), 7.36-7.89 (m, 12H, Ar-H); MS, $m / z(\%): 580\left(\mathrm{M}^{+}, 27\right)$, $582\left(\mathrm{M}^{+}+2\right.$, 9). Analysis for $\mathrm{C}_{30} \mathrm{H}_{22} \mathrm{ClN}_{7} \mathrm{O}_{2} \mathrm{~S}$ (580.06): calcd. $\mathrm{C}, 62.12 ; \mathrm{H}, 3.82 ; \mathrm{Cl}, 6.11 ; \mathrm{N}, 16.90 ; \mathrm{S}, 5.53$. Found C, 62.04; $\mathrm{H}, 3.77 ; \mathrm{Cl}, 5.91 ; \mathrm{N}, 16.78 ; \mathrm{S}, 5.49$.

3.2.14. 5-((4-Chlorophenyl)amino)-9-(3,5-dimethoxyphenyl)-7-oxo-3-phenyl-6,7-dihydro-5Hpyridazino[3,4-b]pyrido[2,3-e][1,4]thiazine-8-carbonitrile (15)

A mixture of $11(0.01 \mathrm{~mol})$, ethyl cyanoacetate $(0.01 \mathrm{~mol})$ and ammonium acetate $(0.01 \mathrm{~mol})$ in n-butanol $(40 \mathrm{~mL})$ was refluxed for $10 \mathrm{~h}$. The precipitate was filtered off, dried and recrystallized from dioxane to give compound 15. Yield 66\%; m.p. 256-258 ${ }^{\circ} \mathrm{C}$; IR $\left(v, \mathrm{~cm}^{-1}\right)$ : 3130, $3166(2 \mathrm{NH})$, $2221(\mathrm{CN}), 1680(\mathrm{C}=\mathrm{O}) ;{ }^{1} \mathrm{H}-\mathrm{NMR}(\delta \mathrm{ppm}): 3.83\left(\mathrm{~s}, 3 \mathrm{H}, \mathrm{OCH}_{3}\right), 3.84\left(\mathrm{~s}, 3 \mathrm{H}, \mathrm{OCH}_{3}\right), 4.40(\mathrm{~s}, 1 \mathrm{H}, \mathrm{NH}$; $\mathrm{D}_{2} \mathrm{O}$ exchangeable), $6.74(\mathrm{~s}, 1 \mathrm{H}$, pyridazine-H), 7.31-7.90 (m, 12H, Ar-H), $8.59(\mathrm{~s}, 1 \mathrm{H}, \mathrm{NH}$ pyridine; $\mathrm{D}_{2} \mathrm{O}$ exchangeable); $\mathrm{MS}, \mathrm{m} / z(\%): 580\left(\mathrm{M}^{+}, 46\right), 582\left(\mathrm{M}^{+}+2,16\right)$. Analysis for $\mathrm{C}_{30} \mathrm{H}_{21} \mathrm{ClN}_{6} \mathrm{O}_{3} \mathrm{~S}(581.04)$ : calcd. $\mathrm{C}, 62.01 ; \mathrm{H}, 3.64 ; \mathrm{Cl}, 6.10 ; \mathrm{N}, 14.46 ; \mathrm{S}, 5.52$. Found $\mathrm{C}, 61.96 ; \mathrm{H}, 3.51 ; \mathrm{Cl}, 5.90 ; \mathrm{N}, 14.29 ; \mathrm{S}, 5.50$.

\subsection{Anti-Viral Bioassay}

Cells: HEPG2 cells were propagated in DMEM medium. They were supplemented with $10 \%$ foetal bovine serum, $1 \%$ antibiotic-antimycotic mixture.

Viruses: a cell culture adapted strain of hepatitis A was provided by Dr. Ali Fahmy, Prof. of Virology at VACSERA (Cairo, Egypt). Virus was titrated to give final concentration $10^{6} \mathrm{PFU} / \mathrm{mL}$.

Synthetic compounds preparation for bioassay: $10 \mathrm{mg}$ of each compound was dissolved in $10 \%$ DMSO and $90 \%$ deionized water, decontaminated with $1 \%$ antibiotic-antimycotic mixture and stored in $-20^{\circ} \mathrm{C}$.

\subsubsection{Cytotoxicity Assay}

The cell culture safety doses of the dissolved synthetic compounds were determined by cell morphology technique [69]. A 96 well plate was seeded with HEPG2 cells and incubated overnight. Synthetic compounds were inoculated at concentrations of 5, 10, 15,20, 25 and $30 \mu \mathrm{g} / \mathrm{mL}$ and observed microscopically for any morphological changes after $24 \mathrm{~h}$ incubation at $37^{\circ} \mathrm{C}$ in a humidified incubator with $5 \% \mathrm{CO}_{2}$. 


\subsubsection{Plaque Infectivity Count Assay}

Plaque infectivity count assay is the most widely accepted method for determining the \% inhibition of virus as a result of being subjected to a given material [70]. A 12 well plate was cultivated with the HEPG2 cells $\left(10^{5}\right.$ cell $\left./ \mathrm{mL}\right)$ and incubated for overnight at $37^{\circ} \mathrm{C}$. Virus was and mixed with the safe concentrations of each compound and incubated for $1 \mathrm{~h}$ at $37^{\circ} \mathrm{C}$. Growth medium was removed from the multi-well plate and virus-compound mixture was inoculated in plate wells. After $1 \mathrm{~h}$ contact time for virus adsorption, $1 \mathrm{~mL}$ of $2 \times$ DMEM medium $2 \%$ agarose overlaid the cell sheet. The plates were left to solidify and incubated at $37^{\circ} \mathrm{C}$ until the development of the viral plaques. Formalin was added for two hours then plates were stained with crystal violet staining solution. Control virus and cells were treated identically without compounds. Viral plaques were counted and the percentage of virus reduction was calculated.

\subsubsection{Mechanism of Virus Inhabitation}

The possible mechanism of HAV inhibition by the compounds was studied at three different levels:

\section{Extract Affects Viral Particle Itself (Virucidal)}

The virucidal assay [71] was carried out in a 12 well plate where HEPG2 cells were cultivated $\left(10^{5}\right.$ cell $\left./ \mathrm{mL}\right)$ overnight at $37^{\circ} \mathrm{C}$. A volume of $100 \mu \mathrm{L}$ serum free DMEM containing $10^{6}$ PFU HAV was added to the concentration of compound resulting in viral inhibition. After $1 \mathrm{~h}$ incubation, the mixture was diluted using serum free medium 3 times, each is 10 fold, that still allows existence of viral particles to grow on HEPG2 cells, but leaves nearly no extract (100 $\mu \mathrm{L}$ of each dilution were added to the HEPG2 cell monolayer). After $1 \mathrm{~h}$ contact time, a DMEM overlay with $2 \%$ agarose was added to the cell monolayer. Plates were left to solidify then incubated at $37^{\circ} \mathrm{C}$ to allow formation of viral plaques and completed as previously mentioned.

\section{Extract Binds to Cell Receptor Preventing Viral Adsorption (Early Replication Step)}

Viral adsorption [72] HepG2 cells were cultivated in a 12 well plate $\left(10^{5}\right.$ cell/mL) and incubated overnight at $37^{\circ} \mathrm{C}$. Compound was applied at different concentrations in $200 \mu \mathrm{L}$ medium without serum and co-incubated with the cells for $2 \mathrm{~h}$ at $4{ }^{\circ} \mathrm{C}$. Unadsorbed compound was removed by washing cells three successive times with serum free-medium. HAV virus (diluted to $10^{4} \mathrm{PFU} /$ well) was then co-incubated with the pretreated cells for $1 \mathrm{~h}$ followed by adding $3 \mathrm{~mL}$ DMEM with $2 \%$ agarose. Plates were left to solidify then incubated at $37^{\circ} \mathrm{C}$ to allow formation of viral plaques and completed as previously mentioned.

Extract Affects One of the Enzymes inside the Cell Needed by the Virus to Complete Its Replication Cycle (Late Replication Step)

A viral replication assay [73] was carried out in a 12 well plate where HEPG2 cells were cultivated $\left(10^{5}\right.$ cell $\left./ \mathrm{mL}\right)$ and incubated overnight at $37^{\circ} \mathrm{C}$. Virus was diluted to give $10^{4} \mathrm{PFU} /$ well, applied directly to the cells and incubated for $1 \mathrm{~h}$ at $37^{\circ} \mathrm{C}$. Unadsorbed viral particles were removed by washing cells three successive times by serum free-medium. Compound was applied at different concentrations, after $1 \mathrm{~h}$ contact time, $2 \mathrm{~mL}$ of DMEM medium supplemented with $2 \%$ agarose was added to the cell monolayer. Plates were left to solidify and incubated at $37^{\circ} \mathrm{C}$ till appearance of viral plaques and completed as previously mentioned.

\section{Conclusions}

Pyridazines have attracted attention because of their easy functionalization at various ring positions, which makes them attractive synthetic building blocks for designing and developing novel pyridazine-containing agents. The incorporation of substituents in the pyridazine ring or as a fused component often leads to incredibly diverse biological activity. The biological profile of these new 
generations of pyridazines is of great interest. This study highlights the status of pyridazinones in the development of novel pyridazinone-based drug candidates as anti-HAV agents. At least one compound (compound 10) has high anti-HAV activity as a result of having a direct effect on the virus (virucidal effect) and also has mild effect on viral replication, so it could be used as a precursor for anti-HAV drugs. The importance of this compound comes from the current lack of antiviral drugs for $\mathrm{HAV}$ and high fatality rates resulting from HAV coinfection with chronic HBV or HCV patients.

Author Contributions: The research group from the National Research Centre Photochemistry Department (Eman M. Flefel, Waled A. Tantawy, Walaa I. El-Sofany, Mahmoud El-Shahat and Ahmed A. El-Sayed) conceived the research project, participated in all steps of the research, interpreted the results, discussed the experimental data and prepared the manuscript. Dina N. Abd-Elshafy from the National Research Centre Water Pollution Department conducted the biological assays and provided the experimental procedures and results. All authors read, discussed and approved the manuscript.

Conflicts of Interest: The authors declare no conflict of interest.

\section{References}

1. Akhtar, W.; Shaquiquzzaman, M.; Akhter, M.; Verma, G.; Khan, M.F.; Alam, M.M. The therapeutic journey of pyridazinone. Eur. J. Med. Chem. 2016, 123, 256-281. [CrossRef] [PubMed]

2. Asif, M.; Singh, A. Exploring potential, synthetic methods and general chemistry of pyridazine and pyridazinone: A brief introduction. Int. J. ChemTech Res. 2010, 2, 1112-1128.

3. Costas, T.; Besada, P.; Piras, A.; Acevedo, L.; Yañez, M.; Orallo, F.; Laguna, R.; Terán, C. New pyridazinone derivatives with vasorelaxant and platelet antiaggregatory activities. Bioorg. Med. Chem. Lett. 2010, 20, 6624-6627. [CrossRef] [PubMed]

4. Mantu, D.; Luca, M.C.; Moldoveanu, C.; Zbancioc, G.; Mangalagiu, I.I. Synthesis and antituberculosis activity of some new pyridazine derivatives. Part II. Eur. J. Med. Chem. 2010, 45, 5164-5168. [CrossRef] [PubMed]

5. Jones, R.A.; Whitmore, A. The tautomeric properties of 6-(2-pyrrolyl)pyridazin-3-one and 6-(2-pyrrolyl) pyridazin-3-thione. Arkivoc 2007, 11, 114-119.

6. Cignarella, G.; Barlocco, D.; Pinna, G.A.; Loriga, M.; Curzu, M.M.; Tofanetti, O.; Germini, M.; Cazzulani, P.; Cavalletti, E. Synthesis and biological evaluation of substituted benzo[H] cinnolinones and $3 H$-benzo[6,7]cyclohepta[1,2-c]pyridazinones: Higher homologs of the antihypertensive and antithrombotic 5H-indeno[1,2-c]pyridazinones. J. Med. Chem. 1989, 32, 2277-2282. [CrossRef] [PubMed]

7. Salvadeo, A.; Villa, G.; Segagni, S.; Piazza, V.; Picardi, L.; Romano, M.; Parini, J. Cadralazine, a new vasodilator, in addition to a beta-blocker for long-term treatment of hypertension. Arzneim. Forsch. 1985, 35, 623-625.

8. Semeraro, C.; Dorigotti, L.; Banfi, S.; Carpi, C. Pharmacological studies on cadralazine: A new antihypertensive vasodilator drug. J. Cardiovasc. Pharmacol. 1981, 3, 455-467. [CrossRef] [PubMed]

9. Fung, M.; Thornton, A.; Mybeck, K.; Wu, J.H.-H.; Hornbuckle, K.; Muniz, E. Evaluation of the characteristics of safety withdrawal of prescription drugs from worldwide pharmaceutical markets-1960 to 1999. Drug Inf. J. 2001, 35, 293-317. [CrossRef]

10. Biziere, K.; Worms, P.; Kan, J.; Mandel, P.; Garattini, S.; Roncucci, R. Minaprine, a new drug with antidepressant properties. Drugs Exp. Clin. Res. 1984, 11, 831-840.

11. Biziere, K.; Kan, J.; Souilhac, J.; Muyard, J.; Roncucci, R. Pharmacological evaluation of minaprine dihydrochloride, a new psychotropic drug. Arzneim. Forsch. 1981, 32, 824-831.

12. Imad, S.; Nisar, S.; Maqsood, Z.T. A study of redox properties of hydralazine hydrochloride, an antihypertensive drug. J. Saudi Chem. Soc. 2010, 14, 241-245. [CrossRef]

13. Cohn, J.N.; Johnson, G.; Ziesche, S.; Cobb, F.; Francis, G.; Tristani, F.; Smith, R.; Dunkman, W.B.; Loeb, H.; Wong, M. A comparison of enalapril with hydralazine-isosorbide dinitrate in the treatment of chronic congestive heart failure. N. Engl. J. Med. 1991, 325, 303-310. [CrossRef] [PubMed]

14. Asif, M. The pharmacological importance of some diazine containing drug molecules. Sop Trans. Org. Chem. 2014, 1, 1-16. [CrossRef] 
15. Li, D.; Zhan, P.; Liu, H.; Pannecouque, C.; Balzarini, J.; de Clercq, E.; Liu, X. Synthesis and biological evaluation of pyridazine derivatives as novel HIV-1 NNRTIs. Bioorg. Med. Chem. 2013, 21, 2128-2134. [CrossRef] [PubMed]

16. Flefel, E.M.; Abdel-Mageid, R.E.; Tantawy, W.A.; Ali, M.A.; Amr, A.G. Heterocyclic compounds based on 3-(4-bromophenyl)azo-5-phenyl-2(3H)-furanone: Anti-avian influenza virus (H5N1) activity. Acta Pharm. 2012, 62, 593-606. [CrossRef] [PubMed]

17. Wang, Z.; Wang, M.; Yao, X.; Li, Y.; Tan, J.; Wang, L.; Qiao, W.; Geng, Y.; Liu, Y.; Wang, Q. Design, synthesis and antiviral activity of novel pyridazines. Eur. J. Med. Chem. 2012, 54, 33-41. [CrossRef] [PubMed]

18. Zhou, J.; Fan, H.-T.; Song, B.-A.; Jin, L.-H.; Bhadury, P.S.; Hu, D.-Y.; Yang, S. Synthesis and Antiviral Activities of $\alpha$-Aminophosphonate Derivatives Containing a Pyridazine Moiety. Phosphorus Sulfur Silicon Relat. Elem. 2010, 186, 81-87. [CrossRef]

19. Ferro, S.; Agnello, S.; Barreca, M.L.; de Luca, L.; Christ, F.; Gitto, R. Synthesis of new pyridazine derivatives as potential anti-HIV-1 agents. J. Heterocycl. Chem. 2009, 46, 1420-1424. [CrossRef]

20. Galtier, C.; Mavel, S.; Snoeck, R.; Andrei, G.; Pannecouque, C.; Witvrouw, M.; Balzarini, J.; de Clercq, E.; Gueiffier, A. Synthesis and antiviral activities of 3-aralkylthiomethylimidazo[1,2-b]pyridazine derivatives. Antivir. Chem. Chemother. 2003, 14, 177-182. [CrossRef] [PubMed]

21. Özadalı, K.; Özkanlı, F.; Jain, S.; Rao, P.P.N.; Velázquez-Martínez, C.A. Synthesis and biological evaluation of isoxazolo[4,5- $d$ ]pyridazin-4-(5H)-one analogues as potent anti-inflammatory agents. Bioorg. Med. Chem. 2012, 20, 2912-2922. [CrossRef] [PubMed]

22. Ochiai, K.; Takita, S.; Eiraku, T.; Kojima, A.; Iwase, K.; Kishi, T.; Fukuchi, K.; Yasue, T.; Adams, D.R.; Allcock, R.W.; et al. Phosphodiesterase inhibitors. Part 3: Design, synthesis and structure-activity relationships of dual PDE3/4-inhibitory fused bicyclic heteroaromatic-dihydropyridazinones with anti-inflammatory and bronchodilatory activity. Bioorg. Med. Chem. 2012, 20, 1644-1658. [CrossRef] [PubMed]

23. Saeed, M.M.; Khalil, N.A.; Ahmed, E.M.; Eissa, K.I. Synthesis and anti-inflammatory activity of novel pyridazine and pyridazinone derivatives as non-ulcerogenic agents. Arch. Pharm. Res. 2012, 35, 2077-2092. [CrossRef] [PubMed]

24. Tewari, A.K.; Dubey, R.; Mishra, A. 2-Substituted-8-methyl-3,6-dihydroimidazo[4,5-c]pyrazolo[3,4-e]pyridazine as an anti-inflammatory agent. Med. Chem. Res. 2011, 20, 125-129. [CrossRef]

25. Abouzid, K.; Bekhit, S.A. Novel anti-inflammatory agents based on pyridazinone scaffold; design, synthesis and in vivo activity. Bioorg. Med. Chem. 2008, 16, 5547-5556. [CrossRef] [PubMed]

26. Faidallah, H.M.; Rostom, S.A.; Basaif, S.A.; Makki, M.S.; Khan, K.A. Synthesis and biological evaluation of some novel urea and thiourea derivatives of isoxazolo[4,5-d]pyridazine and structurally related thiazolo[4,5-d]pyridazine as antimicrobial agents. Arch. Pharmacal Res. 2013, 36, 1354-1368. [CrossRef] [PubMed]

27. Faidallah, H.M.; Khan, K.A.; Makki, M.S.I. Synthesis and Biological Evaluation of New Fused Isoxazolo[4,5- $d]$ Pyridazine Derivatives. J. Chin. Chem. Soc. 2011, 58, 191-198. [CrossRef]

28. El-Mariah, F.; Hosny, M.; Deeb, A. Pyridazine Derivatives and Related Compounds, Part 17: The Synthesis of Some 3-Substituted Pyridazino[3' $\left.4^{\prime}: 3,4\right]$ pyrazolo[5,1-c]-1,2,4-triazines and Their Antimicrobial Activity. Phosphorus Sulfur Silicon Relat. Elem. 2006, 181, 809-818. [CrossRef]

29. Yue, Q.; Zhao, Y.; Hai, L.; Zhang, T.; Guo, L.; Wu, Y. First synthesis of novel 3,3'-bipyridazine derivatives as new potent antihepatocellular carcinoma agents. Tetrahedron 2015, 71, 7670-7675. [CrossRef]

30. Asif, M. The anticancer potential of various substituted pyridazines and related compounds. Int. J. Adv. Chem. 2014, 2, 148-161. [CrossRef]

31. Zhou, S.; Liao, H.; He, C.; Dou, Y.; Jiang, M.; Ren, L.; Zhao, Y.; Gong, P. Design, synthesis and structureactivity relationships of novel 4-phenoxyquinoline derivatives containing pyridazinone moiety as potential antitumor agents. Eur. J. Med. Chem. 2014, 83, 581-593. [CrossRef] [PubMed]

32. Abouzid, K.A.; Khalil, N.A.; Ahmed, E.M.; Mohamed, K.O. 3-[(6-Arylamino)pyridazinylamino]benzoic acids: Design, synthesis and in vitro evaluation of anticancer activity. Arch. Pharm. Res. 2013, 36, 41-50. [CrossRef] [PubMed] 
33. Csókás, D.; Zupkó, I.; Károlyi, B.I.; Drahos, L.; Holczbauer, T.; Palló, A.; Czugler, M.; Csámpai, A. Synthesis, spectroscopy, $\mathrm{X}$-ray analysis and in vitro antiproliferative effect of ferrocenylmethylene-hydrazinylpyridazin3(2H)-ones and related ferroceno[d]pyridazin-1(2H)-ones. J. Organomet. Chem. 2013, 743, 130-138. [CrossRef]

34. Rathish, I.G.; Javed, K.; Ahmad, S.; Bano, S.; Alam, M.S.; Akhter, M.; Pillai, K.K.; Ovais, S.; Samim, M. Synthesis and evaluation of anticancer activity of some novel 6-aryl-2-(p-sulfamylphenyl)-pyridazin-3-(2H)-ones. Eur. J. Med. Chem. 2012, 49, 304-309. [CrossRef] [PubMed]

35. Murty, M.; Rao, B.R.; Ram, K.R.; Yadav, J.; Antony, J.; Anto, R.J. Synthesis and preliminary evaluation activity studies of novel 4-(aryl/heteroaryl-2-ylmethyl)-6-phenyl-2-[3-(4-substituted-piperazine-1-yl)propyl]pyridazin3(2H)-one derivatives as anticancer agents. Med. Chem. Res. 2012, 21, 3161-3169. [CrossRef]

36. Al-Tel, T.H. Design and synthesis of novel tetrahydro-2H-Pyrano[3,2-c]pyridazin-3(6H)-one derivatives as potential anticancer agents. Eur. J. Med. Chem. 2010, 45, 5724-5731. [CrossRef] [PubMed]

37. Sharma, B.; Verma, A.; Sharma, U.K.; Prajapati, S. Efficient synthesis, anticonvulsant and muscle relaxant activities of new 2-((5-amino-1,3,4-thiadiazol-2-yl)methyl)-6-phenyl-4,5-dihydropyridazin-3(2H)-one derivatives. Med. Chem. Res. 2014, 23, 146-157. [CrossRef]

38. Asif, M.; Anita, S. Anticonvulsant Activity of 4-(Substituted Benzylidene)-6-(3-nitrophenyl)-4, 5-dihydroPyridazin3(2H)-ones against Maximal Electro Shock Induced Seizure. Middle-East J. Sci. Res. 2011, 9, 481-485.

39. Banerjee, P.; Sharma, P.; Nema, R. Synthesis and anticonvulsant activity of pyridazinone derivatives. Int. J. ChemTech Res 2009, 1, 522-525.

40. Sivakumar, R.; Gnanasam, S.K.; Ramachandran, S.; Leonard, J.T. Pharmacological evaluation of some new 1-substituted-4-hydroxy-phthalazines. Eur. J. Med. Chem. 2002, 37, 793-801. [CrossRef]

41. Asif, M.; Singh, D.; Singh, A. Analgesic activity of some 6-phenyl-4-substituted benzylidene tetrahydro pyridazin-3(2H)-ones. Glob. J. Pharmacol. 2011, 5, 18-22.

42. Biancalani, C.; Giovannoni, M.P.; Pieretti, S.; Cesari, N.; Graziano, A.; Vergelli, C.; Cilibrizzi, A.; Di Gianuario, A.; Colucci, M.; Mangano, G. Further Studies on Arylpiperazinyl Alkyl Pyridazinones: Discovery of an Exceptionally Potent, Orally Active, Antinociceptive Agent in Thermally Induced Pain. J. Med. Chem. 2009, 52, 7397-7409. [CrossRef] [PubMed]

43. Tan, O.U.; Ozadali, K.; Yogeeswari, P.; Sriram, D.; Balkan, A. Synthesis and antimycobacterial activities of some new $\mathrm{N}$-acylhydrazone and thiosemicarbazide derivatives of 6-methyl-4,5-dihydropyridazin-3(2H)-one. Med. Chem. Res. 2012, 21, 2388-2394.

44. Husain, A.; Ahmad, A.; Bhandari, A.; Ram, V. Synthesis and antitubercular activity of pyridazinone derivatives. J. Chil. Chem. Soc. 2011, 56, 778-780. [CrossRef]

45. Siddiqui, A.A.; Islam, M.; Kumar, S. Synthesis and antitubeculostic activity of 5- $\left\{3^{\prime}\right.$-oxo- $6^{\prime}$-(substituted phenyl)-2' $3^{\prime}, 4^{\prime}, 5^{\prime}$-tetrahyropyridazin-2'-yl $\}$ methyl-2-substituted 1,3,4-oxadiazole. Der Pharm. Lett. 2010, 2 , 319-327.

46. Abouzid, K.; Abdel Hakeem, M.; Khalil, O.; Maklad, Y. Pyridazinone derivatives: Design, synthesis, and in vitro vasorelaxant activity. Bioorg. Med. Chem. 2008, 16, 382-389. [CrossRef] [PubMed]

47. Rathish, I.G.; Javed, K.; Bano, S.; Ahmad, S.; Alam, M.S.; Pillai, K.K. Synthesis and blood glucose lowering effect of novel pyridazinone substituted benzenesulfonylurea derivatives. Eur. J. Med. Chem. 2009, 44, 2673-2678. [CrossRef] [PubMed]

48. Boukharsa, Y.; Meddah, B.; Tiendrebeogo, R.Y.; Ibrahimi, A.; Taoufik, J.; Cherrah, Y.; Benomar, A.; Faouzi, M.E.A.; Ansar, M.H. Synthesis and antidepressant activity of 5-(benzo[b]furan-2-ylmethyl)-6methylpyridazin-3(2H)-one derivatives. Med. Chem. Res. 2016, 25, 494-500. [CrossRef]

49. Wermuth, C.G.; Schlewer, G.; Bourguignon, J.J.; Maghioros, G.; Bouchet, M.J.; Moire, C.; Kan, J.P.; Worms, P.; Biziere, K. 3-aminopyridazine derivatives with atypical antidepressant, serotonergic, and dopaminergic activities. J. Med. Chem. 1989, 32, 528-537. [CrossRef] [PubMed]

50. Lin, H.; Fang, H.; Wang, J.; Meng, Q.; Dai, X.; Wu, S.; Luo, J.; Pu, D.; Chen, L.; Minick, D. Discovery of a novel 2,3,11,11a-tetrahydro-1H-pyrazino[1,2-b] isoquinoline-1,4(6H)-dione series promoting neurogenesis of human neural progenitor cells. Bioorg. Med. Chem. Lett. 2015, 25, 3748-3753. [CrossRef] [PubMed]

51. Contreras, J.-M.; Parrot, I.; Sippl, W.; Rival, Y.M.; Wermuth, C.G. Design, synthesis, and structureactivity relationships of a series of 3-[2-(1-benzylpiperidin-4-yl)ethylamino]pyridazine derivatives as acetylcholinesterase inhibitors. J. Med. Chem. 2001, 44, 2707-2718. [CrossRef] [PubMed] 
52. Biagini, P.; Biancalani, C.; Graziano, A.; Cesari, N.; Giovannoni, M.P.; Cilibrizzi, A.; Dal Piaz, V.; Vergelli, C.; Crocetti, L.; Delcanale, M. Functionalized pyrazoles and pyrazolo[3,4- $d$ ]pyridazinones: Synthesis and evaluation of their phosphodiesterase 4 inhibitory activity. Bioorg. Med. Chem. 2010, 18, 3506-3517. [CrossRef] [PubMed]

53. Giovannoni, M.P.; Vergelli, C.; Biancalani, C.; Cesari, N.; Graziano, A.; Biagini, P.; Gracia, J.; Gavaldà, A.; Dal Piaz, V. Novel pyrazolopyrimidopyridazinones with potent and selective phosphodiesterase 5 (PDE5) inhibitory activity as potential agents for treatment of erectile dysfunction. J. Med. Chem. 2006, 49, 5363-5371. [CrossRef] [PubMed]

54. Siddiqui, A.A.; Mishra, R.; Shaharyar, M.; Husain, A.; Rashid, M.; Pal, P. Triazole incorporated pyridazinones as a new class of antihypertensive agents: Design, synthesis and in vivo screening. Bioorg. Med. Chem. Lett. 2011, 21, 1023-1026. [CrossRef] [PubMed]

55. Thota, S.; Bansal, R. Synthesis of new pyridazinone derivatives as platelet aggregation inhibitors. Med. Chem. Res. 2010, 19, 808-816. [CrossRef]

56. Kumar, D.; Carron, R.; La Calle, C.; Jindal, D.; Bansal, R. Synthesis and evaluation of 2-substituted-6-phenyl4,5-dihydropyridazin-3(2H)-ones as potent inodilators. Acta Pharm. 2008, 58, 393-405. [CrossRef] [PubMed]

57. Sotelo, E.; Fraiz, N.; Yanez, M.; Terrades, V.; Laguna, R.; Cano, E.; Raviña, E. Pyridazines. Part XXIX: Synthesis and platelet aggregation inhibition activity of 5-substituted-6-phenyl-3(2H)-pyridazinones. Novel aspects of their biological actions. Bioorg. Med. Chem. 2002, 10, 2873-2882. [CrossRef]

58. Gelain, A.; Barlocco, D.; Kwon, B.-M.; Jeong, T.-S.; Im, K.-R.; Legnani, L.; Toma, L. Biphenyl versus Phenylpyridazine Derivatives: The Role of the Heterocycle in a Series of Acyl-CoA: Cholesterol Acyl Transferase Inhibitors. J. Med. Chem. 2008, 51, 1474-1477. [CrossRef] [PubMed]

59. Tomori, T.; Miyatake, Y.; Sato, Y.; Kanamori, T.; Masaki, Y.; Ohkubo, A.; Sekine, M.; Seio, K. Synthesis of Peptide Nucleic Acids Containing Pyridazine Derivatives As Cytosine and Thymine Analogs, and Their Duplexes with Complementary Oligodeoxynucleotides. Org. Lett. 2015, 17, 1609-1612. [CrossRef] [PubMed]

60. Ryan, K.J.; Ray, C.G. Medical Microbiology: An Introduction to Infectious Diseases; McGraw-Hill: New York, NY, USA, 2004.

61. Koff, R.S. Hepatitis A. Lancet 1998, 351, 1643-1649. [CrossRef]

62. Wasley, A.; Fiore, A.; Bell, B.P. Hepatitis A in the era of vaccination. Epidemiol. Rev. 2006, 28, 101-111. [CrossRef] [PubMed]

63. Hollinger, F.B.; Liang, T.J. Hepatitis B virus. Fields Virol. 2001, 4, 2971-3036.

64. Rashad, A.E.; Mohamed, M.S.; Zaki, M.E.A.; Fatahala, S.S. Synthesis and Biological Evaluation of Some Pyrrolo[2,3-d]pyrimidines. Arch. Pharm. 2006, 339, 664-669. [CrossRef] [PubMed]

65. Abdel-Aal, M.T.; El-Sayed, W.A.; El-Ashry, E.-S.H. Synthesis and Antiviral Evaluation of Some Sugar Arylglycinoylhydrazones and Their Oxadiazoline Derivatives. Arch. Pharm. 2006, 339, 656-663. [CrossRef] [PubMed]

66. Abdel-Rahman, A.A.H.; Wada, T. Synthesis and Antiviral Evaluation of 5-(1,2,3-Triazol-1-ylmethyl)uridine Derivatives. Z. Naturforschung Sect. C J. Biosci. 2009, 64, 163-166. [CrossRef]

67. El-Sayed, A.A.; El-Shahat, M.; Rabie, S.T.; Flefel, E.M.; Abd-Elshafyc, D.N. New pyrimidine and fused pyrimidine derivatives: Synthesis and anti Hepatitis A virus (HAV) evaluation. Int. J. Pharm. 2015, 5, 69-79.

68. Sayed, H.H.; Hashem, A.I.; Yousif, N.M.; El-Sayed, W.A. Conversion of 3-Arylazo-5-phenyl-2(3H)-furanones into Other Heterocycles of Anticipated Biological Activity. Arch. Pharm. 2007, 340, 315-319. [CrossRef] [PubMed]

69. Aquino, R.; de Simone, F.; Pizza, C.; Conti, C.; Stein, M. Plant Metabolites. Structure and In Vitro Antiviral Activity of Quinovic Acid Glycosides from Uncaria tomentosa and Guettarda platyipoda. J. Nat. Prod. 1989, 52, 679-685. [CrossRef] [PubMed]

70. Tebas, P.; Stabell, E.C.; Olivo, P.D. Antiviral susceptibility testing with a cell line which expresses betagalactosidase after infection with herpes simplex virus. Antimicrob. Agents Chemother. 1995, 39, 1287-1291. [CrossRef] [PubMed]

71. Schuhmacher, A.; Reichling, J.; Schnitzler, P. Virucidal effect of peppermint oil on the enveloped viruses herpes simplex virus type 1 and type 2 in vitro. Phytomedicine 2003, 10, 504-510. [CrossRef] [PubMed]

72. Zhang, J.; Zhan, B.; Yao, X.; Gao, Y.; Song, J. Antiviral activity of tannin from the pericarp of Punica granatum L. against genital Herpes virus in vitro. China J. Chin. Mater. Med. 1995, 20, 556-558. 
73. Amoros, M.; Lurton, E.; Boustie, J.; Girre, L.; Sauvager, F.; Cormier, M. Comparison of the anti-herpes simplex virus activities of propolis and 3-methyl-but-2-enyl caffeate. J. Nat. Prod. 1994, 57, 644-647. [CrossRef] [PubMed]

Sample Availability: Samples of the compounds are available from the authors.

(C) 2017 by the authors; licensee MDPI, Basel, Switzerland. This article is an open access article distributed under the terms and conditions of the Creative Commons Attribution (CC-BY) license (http:/ / creativecommons.org/licenses/by/4.0/). 